\title{
Expandindo a significação em sala de aula de PLE: Encaminhamentos a partir de atividades de livros didáticos
}

\author{
Mariana Lins Escarpinete ${ }^{1}$; Mônica Mano Trindade Ferraz ${ }^{2}$
}

\begin{abstract}
Resumo: O presente trabalho é fruto da observação ao Livro Didático de Português como Língua Estrangeira (PLE) no tocante ao tratamento dado aos aspectos lexicais da língua em suas atividades com vias a aquisição/aprendizagem do Português Brasileiro. Depois de analisado os seguintes livros: 1. Novo Avenida Brasil (volume 1 e 2); 2. Brasil Intercultural: Língua e Cultura Brasileira para estrangeiros (Nível 1); 3. BemVindo! A Língua Portuguesa no mundo da comunicação (Completo), foram selecionadas algumas atividades que incorporavam as relações de sinonímia e antonímia e hiperonímia/hiponímia - fundamentais para a efetivação da aprendizagem de uma língua estrangeira - expandindo a propositura e reflexão da questão, possibilitando uma maior aprendizagem de PLE. A relevância deste trabalho é dada ao papel da Semântica, especificamente ao que concerne ás relações lexicais para o ensino de PLE. Fortificamo-nos na hipótese de que o ensino do léxico na construção dos sentidos no texto é essencial para a formação do estran geiro na língua-alvo, pois, ao pensar a significação na elaboração das práticas de ensino, o repertório vocabular do aprendente vai sendo construído sob a égide do contexto de uso da língua, de comunicação.
\end{abstract}

Palavras-Chave: PLE; Ensino; Semântica; Relações Lexicais; Livro Didático.

\section{Expanding the Meaning in the Classroom of PLE: Referrals from Text book activities}

\begin{abstract}
The present work is the result of the observation to the Textbook of Portuguese as a foreign language (PLE) with regard to the treatment given to the lexical aspects of language in its activities with the acquisition/learning Brazilian Portuguese. After reviewed the following books: 1. Novo Avenida Brasil (volume 1 e 2); 2. Brasil Intercultural: Língua e Cultura Brasileira para estrangeiros (Nível 1); 3. Bem-Vindo! A Língua Portuguesa no mundo da comunicação (Completo), some activities were selected that incorporated the synonymy and relationships on and hiperonímia/hiponímia-essential for the completion of the learning of a foreign language - expanding the filing and consideration of the matter, enabling a greater learning PLE. The relevance of this work is given to the role of semantics, specifically the terms lexical relations ACE for the PLE. Fortificamo us on the assumption that the teaching of the lexicon in the construction of the senses in the text is essential to the formation of the foreigner in the target language, the thinking of the meaning in the development of teaching practices, the vocabulary learner's repertoire is being built under the aegis of the context of use of the language of communication.
\end{abstract}

Keywords: PLE; Teaching; Semantics; Lexical Relations; Textbook.

\footnotetext{
${ }^{1}$ Mestrado em Linguística pelo PROLING/UFPB. Doutoranda / PROLING-UFPB.Contato: mariana_escarpinete@ @otmail.com.

${ }^{2}$ Mestrado em Linguística Aplicada pela Universidade Federal de Santa Catarina e doutorado em Linguística Teórica pela Universi dade Federal de Santa Catarina. Docente na Universidade Federal da Paraíba.
} 


\section{Introdução}

A Língua Portuguesa vem assumindo no contexto internacional uma crescente visibilidade, o que the assegura uma condição de língua a ser pensada aos moldes de uma Língua Estrangeira (LE). Nesse sentido, surge tal vertente de ensino cuja expansão lhe possibilita um status no cenário internacional de proporções bastante significativas. Cunha (2002, p. 33) já registra que essa demanda por cursos em PLE “Talvez (...) esteja ligada à obrigatoriedade de demostrar proficiência em português por parte dos estrangeiros que queiram estudar ou exercer profissões liberais no Brasil". Contudo, esse quadro só se fez possível uma vez da criação, em 1998, do Certificado de Proficiência em Língua Portuguesa para Estrangeiros, variedade brasileira, a saber, CELPE-Bras, o qual, além de constituir-se como avaliação oficial do PLE, dita os parâmetros ${ }^{1}$ de ensino dessa Língua.

Desse modo, tal "prestígio" de procura repercute em um crescente desenvolvimento na oferta do ensino de PLE, contudo, sob uma perspectiva diferente, já que há o elemento da imersão (uma vez que muitos "interessados" vêm em loco aprender o Português). Logo, a aquisição ganha um novo sentido para o aprendente, solicitando uma nova metodologia/abordagem e didática a serem abordadas pelo professor. Ratifica-se o exposto quando analisamos a progressiva busca pela aquisição do certificado de proficiência em PLE, o CELPE-Bras. Nesse contexto, tal exame foi elemento fundamental para a expansão da Língua Portuguesa pelo mundo, uma vez da sua credibilidade e caráter interacional especificamente comunicacional - na avaliação propriamente dita.

Nesse contexto, necessário é uma formação docente eficaz e abrangente, em que o professor possa desempenhar seu papel de modo ativo, respaldado por metodologias que promovam a aquisição da língua de forma interacional, através de uma abordagem pertinente ao caráter do ensino de PLE, a exemplo da utilização do método/abordagem comunicativo, conforme expõe Lúcia Gonçalves Freitas (2009), possibilitando, portanto, uma qualificação do docente em PLE.

Com relação a tornar o ensino mais eficiente possível, destacamos a importância das relações lexicais para o ensino de PLE na prática docente, mais especificamente quando do

\footnotetext{
${ }^{1}$ Não oficialmente assim denominado. 
tratamento dado a este tema pelos Livros Didáticos em Português como Língua Estrangeira. Com esse intuito, analisamos 4 (quatro) Livros Didáticos ${ }^{2}$ de referência no cenário docente em PLE, de autoria nacional e que já passaram, em alguns casos, por revisões interessantes, promovendo a incursão destes na adequada concepção de ensino de língua estrangeira preconizada pelo atual elemento norteador teórico e metodológico desse ensino que é o molde proposto pelo CELPE-Bras.

Foi investigado o papel dado a aquisição vocabular no processo de ensino de uma Língua Estrangeira, no caso, no ensino de PLE - uma vez ser o estudo das relações lexicais elemento de grande valia para a efetivação da aprendizagem de uma língua, estando intimamente ligado aos mecanismos de interação social, efetivados na comunicação, conforme argumenta Nina Fernandes:

\begin{abstract}
O estudo desenvolvido no âmbito do léxico é um desafio evidente quando se fala de uma língua estrangeira. A ênfase é dada ao desenvolvimento da competência lexical para se adquirir um melhor conhecimento sobre o sistema da língua. Ao uso da língua está subjacente, em grande medida, a compreensão do seu modo de funcionamento. Se os falantes de uma língua se expressam através de palavras para exteriorizarem os seus pensamentos, então é crucial que se aprofunde a investigação na área da aquisição do léxico para que possam ser idealizadas, criadas e postas em prática estratégias e actividades que promovam a aprendizagem e o ensino do léxico de uma língua. (FERNANDES, 2009, p. 13)
\end{abstract}

Creditamos o protagonismo nesse processo ao $\mathrm{LD}$, cujo papel não se limita a si mesmo, mas adquire vida e extensão quando da mediação do professor em PLE. Contudo, independentemente de sua "necessidade" de mediação, é fundamental que o LD se apresente de forma ampla em relação às escolhas de conteúdo. Assim, o ensino, como um todo, convoca elementos vários que o fomentam na sua tarefa de desenvolver o conhecimento, e o LD é um desses elementos norteadores para a prática docente. Sendo assim, nada melhor que a presença de uma conduta, nesses materiais, que priorize a comunicação, a interação e outros aspectos da aprendizagem dialogada ${ }^{3}$.

Para que o ensino de uma língua estrangeira se efetive, o docente deve recorrer a uma gama de instrumentos que o auxiliem na condução do processo, visando a que o aluno atinja tanto a aquisição quanto a consequente aprendizagem da língua alvo. Muitos são os recursos possíveis para se lançar mão na tentativa de tornar o aprendente "estrangeiro" proficiente.

\footnotetext{
${ }^{2}$ A partir desse momento, também chamado de LD.

${ }^{3}$ Nã o em termos de abordagem ou método que se utilizam da prática do diálogo na construção do saber, mas em sua a preensão mais geral, denotando necessidade de comunicação para desenvolvimento da compreensão de uma língua. 
Sabemos que, no âmbito do ensino de Língua materna, o meio mais tradicional é a utilização de um Livro Didático que consiga englobar os conteúdos necessário-possíveis para dado nível de conhecimento, sendo também importante seu papel de "bússola" no planejamento e andamento das aulas, conforme o tópico de abordagem do momento.

Apesar do local de destaque do LD para o ensino-aprendizagem de uma língua estrangeira, a produção desse tipo de material no cenário do Português como LE sempre foi muito escassa, fato justificado até pela pouca notoriedade do português como língua estrangeira no "rol da fama" das Línguas Estrangeiras. Quando da sua existência, os LD's nos eram apresentados de modo "preconceituoso", em que as especificidades e particularidades culturais do povo brasileiro eram postas como "malandragem", estereotipando, por assim dizer, condições culturais à condição de caráter de um povo. A língua era reproduzida mecanicamente, sem uma apreciação de contexto de uso. Felizmente, a postura mediante tal área de atuação já vem senso transformada. Novas obras têm sido lançadas, antigos manuais têm sido reorganizados e editados, "velhas posturas" têm se transformado, assimilando teorias e técnicas de ensino mais modernas; livros são produtos nacionais, escritos, editados e organizados por autores brasileiros, colocando o Português Brasileiro no escopo das línguas estrangeiras.

Isto posto, foram selecionados os livros: Novo Avenida Brasil (NAB), tanto o volume 1 , quanto o 2, sendo estes dois volumes parte de uma coleção maior que passou por reedição bastante expressiva e produtiva, adequando-se aos atuais conceitos teóricos de língua em uso. Aspecto de também interessante dessa obra diz respeito à sua visibilidade no cenário de PLE, sendo uma coleção já consagrada na área, daí também nossa escolha. Brasil Intercultural: Língua e Cultura Brasileira para estrangeiros (Nível 1) (BI), neste, o cunho gramatical é deixado em segundo plano, quando evidenciado. A prioridade é para o aspecto cultural, sendo trabalhados os aspectos de comunicação e interação intercultural. Bem-Vindo! A Língua Portuguesa no mundo da comunicação (Completo) (BV), apresenta uma abordagem comunicativa, evidenciando a interação no contexto de inserção do aluno.

Cabe-nos reforçar que o conteúdo semântico interessado são as relações de sinonímia e antonímia, hiperonímia/hiponímia - sendo as últimas provedoras de processos de categorização que estão para a construção dos chamados campos lexicais e também associativos -. Assim, segundo Brink, concordamos que: 
A aula de uma determinada LE torna-se um espaço sem fronteiras em que as características da LA, especialmente no que diz respeito ao léxico, são constantemente comparadas, ligadas ou contrastadas com as outras línguas utilizadas e estudadas pelos alunos. Criam-se, assim, condições para uma aprendizagem mais eficaz estimulando o desenvolvimento da competência plurilingue. (BRINK, 2001, p. 73)

Feita a observância aos referidos livros, para este trabalho, propomos um detalhamento quanto às atividades já existentes, proporcionando, em caráter mais sugestivo, uma expansão do trabalhar com a significação em sala de aula, construindo algumas questões/atividades (não tão sistemáticas já que se trata de uma sugestiva), que sejam relevantes, dando visibilidade ao estudo do léxico em sala de aula de PLE. Nossa intenção não é desenvolver uma série de atividades a compilar um manual, mas sugerir um tipo de abordagem que cremos mais adequada para a efetivação da competência lexical para a aquisição de determinada língua, no nosso caso o PLE.

\section{O Estudo do Léxico em PLE}

$\mathrm{Na}$ esteira do exposto até o momento, faz-se indispensável refletirmos sobre este aspecto da língua tão funcional ${ }^{4}$ para o entendimento dos usos da linguagem, a saber, a significação enquanto promotora da aprendizagem no ensino de uma língua (tanto em seu recorte nativo - Língua Materna -, quanto estrangeiro - Língua Estrangeira, Segunda Língua e Língua de Herança -).

Nossa predileção pelo estudo do significado das palavras nas relações lexicais se dá, conforme defendido por Kleimam, uma vez que "o domínio do vocabulário é parte essencial do aprendizado da língua e dele depende o desenvolvimento da proficiência em leitura e escrita" (apud BEVILACQUA, 2006, p. 144). Para tanto, é fundamental que a escola, o ensino e o docente tenham esta concepção muito bem estabelecida a fim de possibilitar uma aprendizagem significativa e ampla.

${ }^{4}$ Funcional no sentido de funcionalidade, não de Funcionalismo. 
lexical que envolve reconhecimento e uso das palavras em situações adequadas. (BEZERRA, 1999, apud BEVILACQUA, 2006, p. 144)

Assim, partimos do reconhecimento da importância de uma aprendizagem que proporcione o desenvolvimento lexical para a efetivação da aprendizagem de uma Língua Estrangeira. Não basta apenas "reconhecer palavras, mas aprender com as palavras" (Vareza, 1994, apud Bevilacqua 2006, p. 144). Para isso, o Léxico deve ser considerado como parte constitutiva essencial de uma língua, em que o estabelecimento de um domínio vocabular se faz extremamente relevante para a escolha de um repertório específico de palavras em um determinado contexto comunicacional. Dito de outro modo, é através do ensino pautado nas questões de cunho lexical que se estabelece uma autonomia dos aprendizes com relação ao manejo da língua alvo nas esferas de comunicação solicitadas pelos gêneros textuais, por exemplo. Então,

Se o Léxico é entendido como o sistema das palavras de uma língua, logo, é através dele que se activam os conhecimentos e se estabelecem ligações conceptuais para se operar a comunicação. Esta é realizada por meio de palavras que se combinam entre si. (FERNANDES, 2009, p. 37)

Em outras palavras, sendo o Léxico o "sistema de palavras", e a palavra parte essencial para a aquisição, corroboramos que

\footnotetext{
Conhecer a palavra (...) tem a ver com (1) não só reconhecê-la, mas também saber usá-la no momento e no contexto adequados, facilitando a comunicação entre interlocutores, e (2) não só perceber os efeitos de sentido por ela exercidos, mas também saber relacionar a palavra que venha exercer no interlocutor o efeito de sentido pretendido. (BEVILACQUA, 2006, p. 140 , grifos nossos)
}

Concluímos, portanto, que nossa hipótese se faz pertinente e cabida de investigação, tão logo da certeza de que olhar para a questão da significação em sala de aula de PLE possibilita a formação de alunos proficientes na língua, uma vez que o adequado domínio lexical é uma das condições para que a efetiva comunicação se estabeleça, contanto que o devido direcionamento aconteça.

É bastante pertinente acreditar que através do conhecimento das relações lexicais o aluno em PLE não só vai adquirir a língua, as palavras que a regem (podendo fazer-se de forma solta e desconexa de um todo comunicativo), mas, de modo mais hábil, o aluno vai estabelecer o conhecimento e reconhecimento da realidade de uso em que se está inserido. É nesse conhecimento que se estabelecerá a relação entre língua e cultura tão valorizada, de 
modo oficial, pelo Quadro Comum Europeu de Referência, em que o plurilinguísmo e a interculturalidade são postos como saberes substancias para o domínio de uma LE.

Nesse passo, caminhamos ao encontro da concepção de ensino, especificamente de PLE, que priorize a aprendizagem das relações lexicais que vão além da própria frase, que ultrapassem a simples conceituação de itens lexicais que desfavorecem o uso (em que a básica tradução dos termos é solicitada), sem que se exija do aprendente um esforço de empregar e reconhecer tais palavras nos nossos contextos discursivos, na nossa realidade comunicacional. $\mathrm{O}$ ideal seria levar $\mathrm{o}$ aluno a se familiarizar com as palavras em diferentes situações comunicativas, levando a possibilidades de representação destas conforme variasse a situação. Dessa forma, não bastaria a aprendizagem de listas de palavras, como por exemplo, uma lista de sinônimos e antônimos, para proporcionar a adequação de uso, contudo a permissão de criação dos significados assumidos pelas palavras, garantindo o uso efetivo da linguagem.

\footnotetext{
O combate à fuga das palavras de uma língua estrangeira faz-se com uma comprometida participação de todos os intervenientes no processo de aquisição de uma língua. Este compromisso deve incidir na elaboração de estratégias que instiguem ao desenvolvimento de competências, em particular, a lexical, de forma faseada e consecutiva. (FERNANDES, 2009, p. 36)
}

\section{Extrapolando os limites do encontrado}

Mediante de todas as observações, constatações, indagações e ponderações no que diz respeito à apreciação feita ao Livro Didático em PLE, concluímos que a realidade se mostra, em alguns momentos, com perspectivas ultrapassadas para o ensino de uma língua estrangeira - estando aquém das teorizações que fornecem novas diretrizes para trabalho - e, em outros momentos, caminhando na direção de uma aprendizagem mais consistente, pautada nos aspectos da comunicação, da língua em situação real de uso - trabalhando com os gêneros textuais de forma direta, ou, capacitando o aluno ao bom desenvolvimento da interação na língua.

Como já foi dito anteriormente, o Livro Didático deve ser considerado como o elemento capaz de promover essas questões, como um recurso indispensável à aula de PLE. Assim sendo, espera-se que ele contenha as mais variadas estratégias de consolidação dessa 
aprendizagem, "abusando" das questões de cunho semântico e pragmático, por favorecer o domínio, a competência lexical do aluno, além de fazê-lo reconhecer e entender as nuances da comunicação típicas de quem maneja a língua com presteza.

Considerando, então, que o LD por si só não cumpre com esse papel, propomos uma reflexão que leve à extrapolação das questões referentes às relações lexicais evidenciadas. E é com essa inquietação sobre a "incompletude" dos LD's que o nosso estudo vai caminhando, voltando atenção para sugestões de um possível tratamento mais adequado a tais recursos para o ensino de PLE, solidificado pela convicção de que

\begin{abstract}
A visão de proficiência ou do que é saber uma língua, portanto, necessariamente definida pela visão da linguagem, também delimita a natureza dos métodos ou maneiras de ensinar, dos materiais didáticos e dos procedimentos e instrumentos de avaliação. Para avaliar a "linguagem como ação no mundo", os instrumentos teriam, sobretudo, que focalizar o desempenho do aluno em situações que envolvam a construção de sentidos e não apenas se o mesmo é capaz de manipular formas gramaticais. (SCARAMUCCI, 2006, p. 59-60)
\end{abstract}

E é exatamente essa a matéria em questão, proporcionar a conscientização de que o direcionamento seria mais interessante para fortalecer a perspectiva posta em destaque por Scaramucci.

Com esse raciocínio, não é o nosso interesse desenvolver uma espécie de apostila ou compêndio de utilização didática como se propõe um livro propriamente dito, todavia, intencionamos apresentar algumas considerações extras sobre possibilidades de práticas em sala de aula com o tópico preconizado. Assim, nosso direcionamento será no nível de um ideal necessário que leve o aluno a reconhecer o léxico da língua não de forma estanque e prototípica, atribuindo o caráter de perfeitos (no caso dos sinônimos e antônimos) e préestabelecidos (no caso dos hiperônimos relacionados com hipônimos exclusivos), mas com vias à percepção do papel do contexto nesse processo, enaltecendo tanto o nível semântico quanto o pragmática da comunicação.

Desse modo, ambicionamos promover uma aproximação com os parâmetros estabelecidos pelo exame CELPE-Bras, instrumento fundamental para mensurar os níveis de proficiência do estrangeiro em relação à língua portuguesa na variante brasileira, através de direcionamentos mais específicos para a ampliação vocabular do aluno, a ser evidenciada através da produção de gêneros textuais.

Dando continuidade à ênfase no léxico, comungando do afirmado por Irandé Antunes (2012, 161), “o ideal - para fins de estudo do léxico - seria que o livro didático não fosse a 
única fonte do material trazido para a sala de aula". Assim, é possível afirmar que os livros devem servir como um dos mais expressivos instrumentos de ensino, todavia, é preciso que seja conjugado ao LD um direcionamento mais particular, com materiais adicionais e, essencialmente, uma prática docente interferindo com vias à facilitação, à aprendizagem.

Esperamos que o entendimento seja mais amplo quanto à importância do léxico nas atividades do LD, e, para ratificar essa relevância, almejamos proporcionar uma variedade de sugestões para que estes tópicos lexicais tenham o devido tratamento, daí,

\footnotetext{
É uma questão de puxar pela imaginação e, no andamento do mesmo curso, ir inventando e criando oportunidades para que o aluno entre pelo universo do léxico e alcance o acervo de palavras-conceitos-expressões que tem a seu dispor. (ANTUNES, 2012, p.161)
}

Nesse sentido, iniciamos com a elaboração de sugestões referentes às relações de sinonímia e antonímia, aproveitando-nos de atividades já avaliadas neste estudo. Da mesma forma, deter-nos-emos, em seguida, na relação de hiperonímia/hiponímia, propondo um desenvolvimento para as atividades já existentes.

Através do apreendido até o momento sobre a atenção dada pelos LD's selecionados para análise ao que diz respeito aos processos semânticos de sinonímia e antonímia, é possível assegurar que o material não consegue dar conta, em alguma medida, das particularidades para o ensino das relações lexicais. Apesar de apresentarem algumas poucas questões nesse sentido, de forma geral, são superficiais e não apresentam um fim objetivo e claro.

Assim, as atividades tornam a aquisição e a aprendizagem do léxico sem considerar o grande protagonista da cena: o contexto. As palavras são concebidas independentes do processo de comunicação, isoladas dos aspectos reais de interação, ou então (o que já é bastante lucrativo) em forma de frases, como se essas fossem a representação maior da linguagem. Esquece-se que a linguagem se concretiza em textos, pois toda a interação é realizada por meio de textos, de gêneros textuais, dito por Antunes (2012), em uma perspectiva de linguagem enquanto ação discursiva, explorando-se o conhecimento lexical como edificador das competências de fala, compreensão, leitura e escrita.

Podemos, ainda, afirmar que, ao que se presta, o LD consegue introduzir os conceitos para os aprendentes estrangeiros, mas, por si só, fica a desejar. Nesses termos, é necessário que se faça presente uma espécie de intermediação, na figura do professor em PLE. Seria até razoável considerar que o Livro Didático já conta com essa intervenção, pois é como se 
existisse um "acordo de cavalheiros" implícito entre o suporte e o utilizador, permitindo-se, o manual, nesse sentido, proceder com solicitações pouco instrutivas e/ou com atividades sem aprofundamento.

A partir dessa possibilidade, vamos propor uma continuidade a algumas atividades para que esse acordo seja bem cumprido.

O exercício que se segue possui um caráter mais contextual, verificável na utilização de fragmentos de um texto fonte, em que as palavras são destacadas para a devida associação. Entretanto, para que esse elemento fundamental seja bem explorado, é necessário estender a reflexão.

Esse caráter contextualizado pode ser mais bem observado com o devido trabalho do texto, fazendo com que o aprendente perceba que as palavras, a partir de uma realidade de uso, vão selecionando um dos seus muitos sentidos. Imbuídos nessa perspectiva, o ensino do vocabulário tem que ser construído, entendendo que,

... esse problema tende a ser minimizado se houver uma orientação adequada em sala de aula,
ou seja, se professores e produtores de livros didáticos mudarem sua postura frente ao ensino
do vocabulário, contribuindo para que o aluno se conscientize de que reconhecer e identificar
itens lexicais, substituí-los por sinônimos ou indicar seus antônimos são apenas alguns dos
aspectos envolvidos no conhecimento de uma palavra. (GATTOLIN, 2006, p. 140)

Sendo assim, nossas proposições para a atividade 2 do BI tendem para essa perspectiva reflexiva da língua, em consonância com o solicitado pelo exame de proficiência, orientador do ensino e cujo foco na produção de gêneros textuais e orais leva à compreensão de que, para que haja êxito no que é pedido, o aluno deve ter não somente o léxico, mas também a capacidade de o empregar adequadamente no gênero delimitado, observando, por exemplo, qual o grau de formalidade requerido pelo gênero.

Pretendendo adequar as informações instruídas acima que asseguram uma aprendizagem eficiente, nosso desejo é abordar o item lexical em exposição de forma ainda mais detalhada, permitindo, assim, um resultado mais significativo. Vejamos a atividade: 
Id on Line Revista Multidisciplinar e de Psicoloqia

Id on Line Multidisciplinary and Psycology Journal

BI - p. 30

2

Apos a lettura do texto, telacione as palavras expressóes abalxo com outras que aprosentem o mesmo sentido.

(1) - Se um casamento nao da rerto, botam a culpa na rotina." (Jinhas)

(2) Tusa ma fama, que assodia a palavia a tudo o que é tedioso." (linha 3)

(3) "Um casal amigo meu todo ano vai a Paris e a algum outro lugar." (linha 5)

(4) "Set de um sujeito - Inerivel * que dis uma escapada todo ano com a ex-esposa." (tinha 7)

(5) "Pata alguns parecerao virtudes um pouco caretas, mas nem por isso săo descartáveis." (linha 90$)$

(6) "E tente destrutar um bom momento de amor sem algumas delas." (linha "1)

(7) "No coesasa, ela se chama ritrno: sem ela, pifamos." (Uinha 13)

(B) "Ja pensaram que canselra se o coraço batesse descompassado a cada minutor" (linha is)

(9) Toda semana a gente se telefona." (linha 20)

(vo) "o outono, corn seus ventos a varret folhas apos a colheita." (linha 35 e 36 )

() curtirf aprovehtar

() ligar

( ) conservadoras

() fugir

() as.lo de colher os produtos da terra

( ) parfdupla

() ruim

() colocar

( ) parar de funcionar

( ) palpitar

O ideal não é tão-somente selecionar a palavra que melhor se adeque ao contexto suscitado, é, para além disso, levar o aluno à compreensão de que essas mesmas palavras podem assumir ainda outros sentidos se utilizadas em outras sentenças.

Defendemos, então, que essa questão poderia ter continuidade, por exemplo, ao acrescentar uma atividade de número 3 , adotando a seguinte solicitação:

2. Considerando que as palavras destacadas nos fragmentos da questão anterior assumem o sentido exposto pelo sinônimo assinalado como resposta, formule novas sentenças, embasadas nas experiências com a língua, em que essas mesmas palavras destacadas assumam um sentido ainda diferente do sinônimo marcado como resposta. 
É através de mais uma atividade, a exemplo da recomendada acima, em que os sinônimos vão sendo construídos no uso, que o aluno é direcionado ao entendimento principal da relação, ou seja, a não existência de sinônimos perfeitos e exclusivos, bem como é através desse tipo de indicação que se consolida o tratado por Leffa (1996), nas palavras de Gattolin:

\footnotetext{
... conhecer os diversos aspectos de uma palavra permite a leitores e tradutores desfazer ambiguidades lexicais de modo mais eficiente do que quando recorrem ao apoio do conhecimento de mundo, o que confirma sua hipótese (de Leffa), fundamentada "na premissa de Filmore de que uma palavra é conhecida pela companhia com que anda". (GATTOLIN, 2006, p. 142)
}

A nossa próxima atividade foi utilizada também na análise para ser descrita e avaliada. Nesse momento, proporemos uma continuidade, ou melhor, uma reorganização para que o léxico seja trabalhado com vias ao desenvolvimento do domínio lexical do aprendente, uma vez que, como está, a atividade não possibilita uma aprendizagem lexical, contribuindo para uma autonomia dos alunos envolvidos no processo.

NAB 1 - p. 35

1. Como pode ser?

O condomínio é caro.

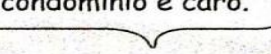

A garagem é baixa.

\begin{tabular}{|c|c|c|c|}
\hline $\begin{array}{l}\text { a garagem } \\
\text { o aluguel } \\
\text { o condomínio } \\
\text { o vizinho } \\
\text { o elevador } \\
\text { o prédio } \\
\text { a sala }\end{array}$ & $\begin{array}{l}\text { bonito } \\
\text { novo } \\
\text { baixo } \\
\text { claro } \\
\text { caro } \\
\text { ensolarado } \\
\text { barulhento }\end{array}$ & 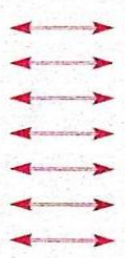 & $\begin{array}{l}\text { feio } \\
\text { velho } \\
\text { alto } \\
\text { escuro } \\
\text { barato } \\
\text { úmido } \\
\text { tranquilo }\end{array}$ \\
\hline
\end{tabular}

$\mathrm{Na}$ tentativa de reorganizar essa atividade, recomendamos, a partir da sua solicitação principal, uma nova abordagem. Aqui, vale dar ênfase para o fato de que não é o foco trabalhar com antônimos, mas, formular sentenças predicativas com o auxilio de um quadro de pares opositivos, apresentados de maneira a tornar o aprendente incapaz de reconhecer as várias outras possibilidades de associação, permitindo, de modo indireto, o entendimento de que a antonímia se estabelece de forma perfeita e exclusiva, isolada de um contexto de uso. Para contrariar tal constatação, propomos a seguinte continuidade: 


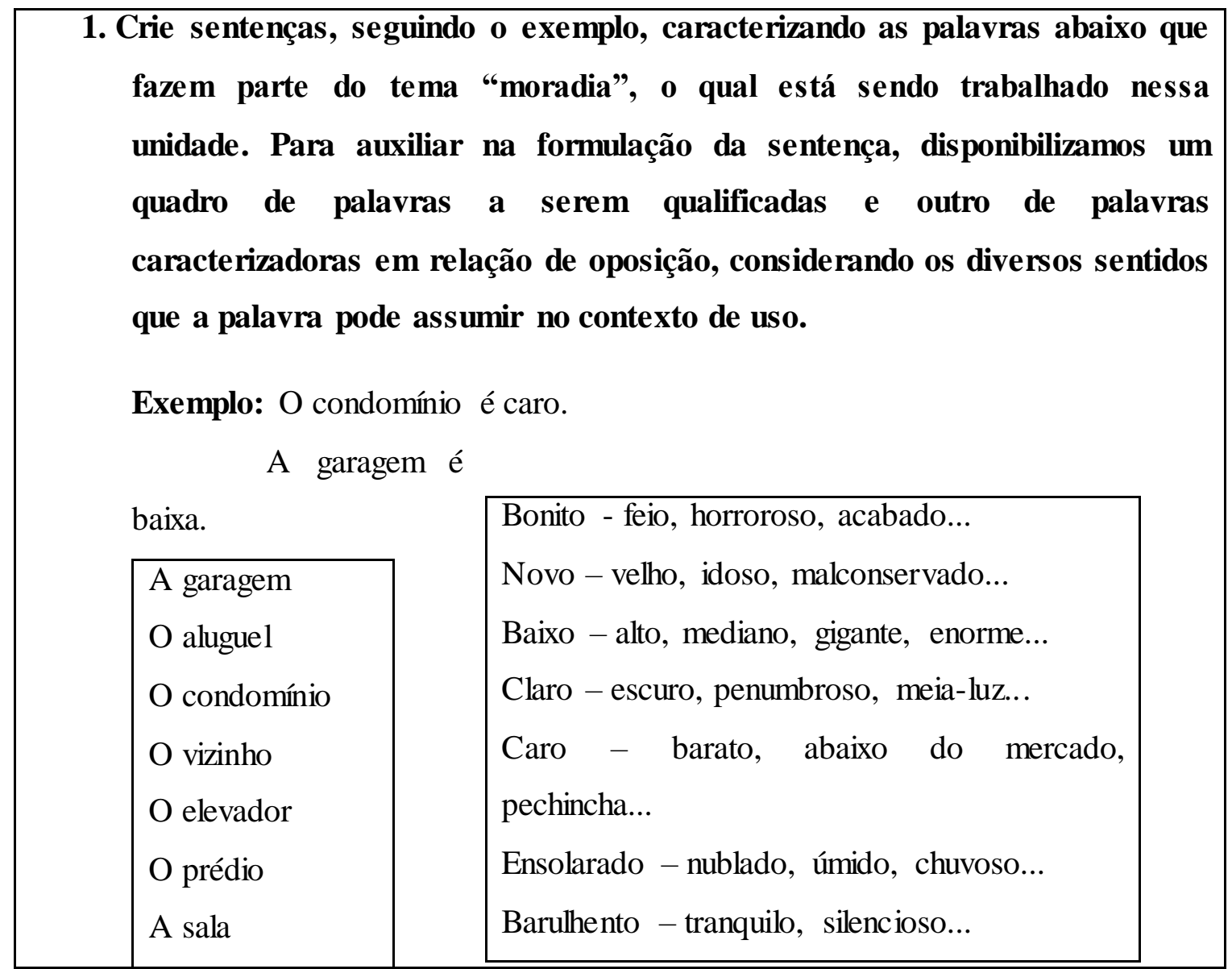

Essa proposta, apesar de ser mais detalhada e extensa, consegue trazer à tona informações importantes para a sua resolução, bem como deixa esclarecido que a antonímia, assim como a sinonímia, é uma relação entre palavras, no caso, opostas, variável e moldável ao que se quer expressar, não vista como uma associação exclusiva entre termos. Extrapolando esse caráter, a atividade promove uma contextualização com propósitos e objetivos bem específicos, esclarecendo os limites para a avaliação, permitindo, assim, que se cumpra com o esperado pela atividade.

$\mathrm{O}$ exercício seguinte foi retirado do livro $\mathrm{BV}$, o qual, dentre os avaliados, possui uma abordagem mais próxima do preconizado pelo CELPE-Bras, isto é, o conhecimento vai sendo fomentado gradativamente através da utilização de excessivos textos, antecedendo as solicitações. Os itens lexicais são trabalhados implicitamente, não com atividades de criação de associações isoladas de palavras, mas, quando sistematizados, através da criação de 
Id on Line Revista Multidisciplinar e de Psicoloqia

Id on Line Multidisciplinary and Psycology Journal

combinações criadas pelo aluno a partir de um contexto de uso proposto, conforme veremos

na questão em relevo:

\section{BV - p. 184}

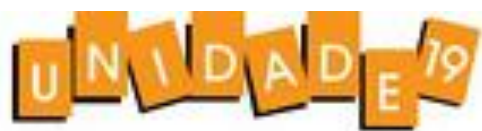

\section{ESSA MENINA VALE OURO}

Com humildode, coriumo e determinogoo, a poicho Doiane dos Samtos, de 21 anos, devou seu nomse gravado na hindria do gindatica olimpica. Fla ganhou mois uma medolhe do ouno na poovn de sola. Dento vea foi no etopo de Coltus (Alemo: nha) da Copa do Munda. A adota foi opladida do pe por um poblice que deliravo o coda pirueta de sev diplo mortal esticodo. Com o teito, Dainere somourse a primetro brasileiro a alcançar o topo do ranking mundial da modalidade solo

E paxada a rotina do ginosta, que for descoberto aos 11 onod enquanto brincavo numa pro: oinha de Porto Alegre. Altm dos eanreicios, ela fae Fisioleropia preveréivo, pard evilar lasbes. Depois dos treinos, oinda vo pora a foculdode dirigindo seu $\mathrm{Ka}$ vermelha. Esta curiando Educoço Fisica $o$, no futuro, espora ser fibcrica do ginditica ou personol troines.

Nos raros momentos de folga, Doiane gosta de pegar um cimema e de sair para dancar pogado, amo, regpoe e funk em Curitba, onde mora. Fona do oinasia, troco o colorte por modeltos que deivem a montro o piercing no umbigo e a foluogom de logorlo que tae nos costos.

Vaibosa, a clleta fat a prósria moquiogens onter das apresertoxhen. Des que noo se incomoda rom a boive eitoturo, de 1,45 metros. 'E nunco solfi com proconceito por seer nogra." Anles das provos, abre mbo do eslrogonole, seu pralo perdorido, e cai de boca nos cortroidretos, por sereen de fock diperbo.

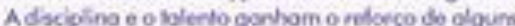
lolamoda: una corroesínha com a modah ha de Santo Antbrio, um lenceiro olho, uno entrela de Dovi e

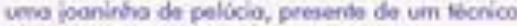
eppanhol, em 1999. "Dd sorte", gorunts.

Em Asenaw, Daiane divw motrar wa nova coreogrofio, Bronileirinha. 'Ela voi reolmente sombor, o que nenhumo oulra ginasta fard", comenta Khory Ferreito, que monfou a apretentagbo de Daiane. Ele explico aindo que a corecoprafio teró sons de berimbor, avica e a bohucoda dos escolias de sambo Mangueina e Beja-Flot.

Srav leirinho s uma das armes de Daiane paro tentar tomor reol o sorko do medotho olimpion.

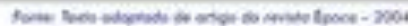

Observe como a palavra CONQuISTA é apresentada no dicionário:

- após a palavia CONQUISTA temos a explicaça da origem da palavra e o significado original;

- seguem-se as iniciais S. f., que indicam a sua categoria gramatical (um substantivo feminino);

- temos entalo as definiços da palavra;

- o dicionario apresenta ainda a palavra CONQUISTADO com a funço de Adj. (adjetivo), sua definiçáo e os sinónimos; e o termo CONQUISTADOR, com duas funçós: a de Adj. (adjetivo) e a de S. m. (substantivo masculino), seguido de suas definiçoses, uma delas Fam. (familiar).

Em uma folha separada, faça o mesmo ESTUDO das palavras: HUMILDADE, DETERMINACAO, GINASTICA, DELIRAR, PREFERIDO, FOLGA, APLAUDIDA, FEITO. a. escreva frases com os DERIVADOS, SINONIMOS oU ANTONIMOS das palavras listadas.

b. verifique os diversos usos da palavra PEGAR (pegar um clnema, por exemplo). 
Além do texto de onde a palavra conquista é retirada e evidenciada, com uma espécie de conceituação dicionarizada, há uma espécie de construção de um roteiro explicativo do que o dicionário traz para a palavra, de forma a ilustrar a futura resposta do aluno. Isto posto, pede-se que o aluno faça o estudo das palavras selecionadas no quadrinho azul, seguindo, então, o modelo de conquista, bem como para que escreva frases com derivados, sinônimos ou antônimos das palavras listadas. Por fim, vem a solicitação mais importante: verificar os diversos usos de pegar. Cremos que esse é um exemplo de atividade que está bem adequada ao preconizado para o desenvolvimento da competência lexical, vista aqui como

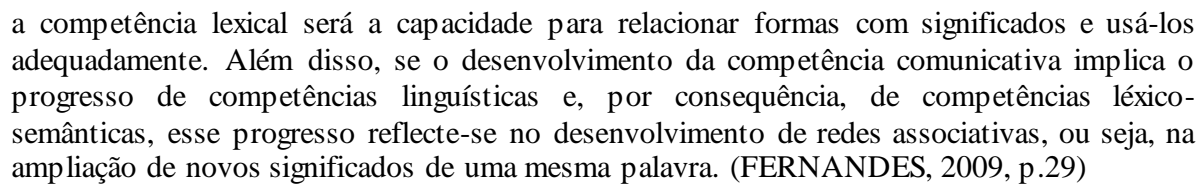

Entretanto, a questão ainda pede um tratamento mais aprofundado sobre o caráter polissêmico da palavra, a exemplo de pegar posto em destaque no quadrinho da proposta. Esse detalhamento não precisa ser possibilitado por uma sugestão de atividade em si que dê continuidade ao apresentado, mas pode ser praticado pelo docente em sala de aula. Daí, faz-se um recorte da questão, pois evidencia-se que, além desta, várias outras palavras podem assumir diferentes sentidos a partir do contexto de uso em que se está inserido, selecionando, para cada uma das possibilidades de sentido atribuída, um sinônimo e um antônimo diferente. Logo, a premissa comunicativa que deve servir de "bússola" para o ensino se consolida ao observarmos, nesse direcionamento, que "a abordagem comunicativa desloca o centro da gravidade na dupla operação que caracteriza a tarefa do aprendiz: trata-se não de aprender para depois comunicar, mas de ligar intimamente o aprender ao comunicar" (MARTINEZ, 2009, p. 72).

Dando sequência ao nosso estudo, ou melhor, às sugestões de atividades, focalizaremos na relação indissociável da hiperonímia/hiponímia. A partir do aproveitamento das atividades, propomos uma continuidade na reflexão do léxico, ou uma reestruturação da atividade para que o tratamento a essas relações seja mais pertinente. 
NAB 1- p.77
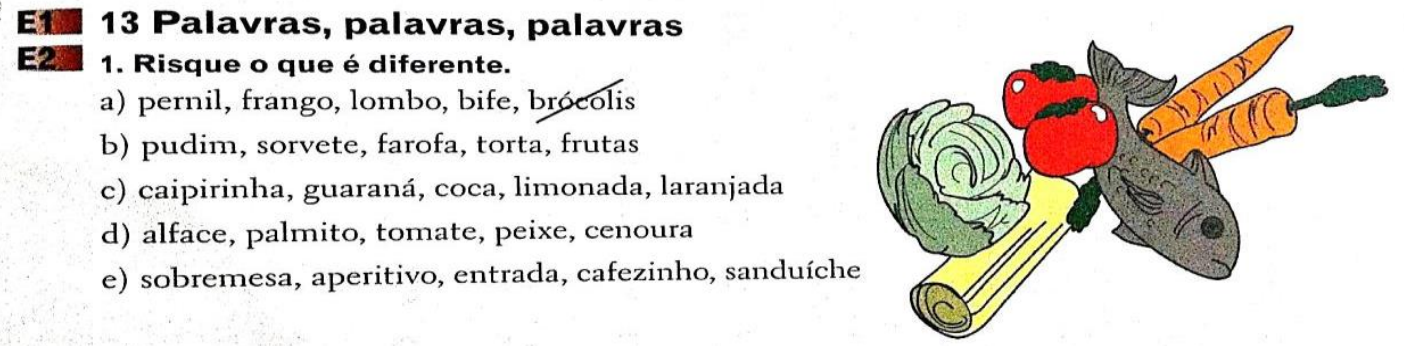

Uma possibilidade é o estabelecimento de critérios de categorização. Conforme analisamos nessa atividade, a maior problemática está na falta de clareza do componente selecionado para a diferenciação, assim, é possível que se forneçam os critérios desejados para a resolução adequada. Outra possibilidade, até mais pertinente, é a continuação da questão 1 com a seguinte solicitação:

\section{Após riscar o que é diferente em cada grupo de palavras listadas nas alternativas acima, apresente sua resposta para a sala, explicando qual o critério de categorização selecionado por você para selecionar dada palavra como diferente do seu grupo.}

A ideia aqui é promover a discussão desta questão, superando a própria atividade. Dessa forma, é provável que, a partir da participação conjunta dos aprendizes, haja o entendimento de que as palavras podem fazer parte de campos lexicais diferentes a depender do contexto de uso em que está inserida.

\section{Conclusão}

Desta sorte, cremos que, com direcionamentos desse tipo, sugeridos aleatoriamente e despretensiosamente nesta seção, será colocada em prática a defesa do estudo das relações 
lexicais, tanto de sinonímia e antonímia, hiperonímia/hiponímia, como de muitas outras que perfazem a especificidade da língua portuguesa em moldes estrangeiros.

O ensino que gere a ampliação vocabular, a percepção de que as palavras são fontes de múltiplos sentidos, os quais se revelam no uso, na comunicação, na interação com os falantes na comunidade de fala em que o estrangeiro está exposto, cuja cultura determina muitas dessas relações, proporciona a efetivação de uma aprendizagem consciente das combinações permitidas pela língua.

Mais ainda, é com esse olhar que se prioriza o aspecto textual que é inerente à linguagem e que preenche as páginas do CELPE-Bras. Não pretendemos dizer que a importância essencial está nesse exame que trabalha com essas questões de gênero, mas ao contrário, é exatamente, pela importância das questões de gênero - imbricadas no uso - que o CELPE se consolida, sendo esse uma espécie de agente para que de igual modo o ensino se baseie, ganhe novas "rotas". Assim, de acordo com esta acepção e com a expressividade do defendido até o momento, podemos dizer que, a despeito de

\footnotetext{
O número de professores e produtores de materiais desinformados sobre o papel da competência lexical na competência comunicativa, (...) a única conclusão permitida nesse momento é a de que muitas outras pesquisas ainda se farão necessárias para que esses profissionais revejam suas concepções do que seja ensinar e aprender vocabulário, do que seja competência lexical, definida em termos de um conceito rico, e do que ela representa para o falante de uma língua - seja ela materna ou estrangeira. (GATTOLIN, 2006, p. 154)
}

E é nesse sentimento que enveredamos para as últimas considerações deste estudo, crendo que a porta está aberta para que os responsáveis pelo ensino de Português como Língua Estrangeira adentrem, conscientizando-se do longo caminho que se tem pela frente.

\section{Referências}

BEVILACQUA, C. R. Ensino e Aprendizagem de línguas: língua estrangeira. 2006- Ijuí: Ed. Unijuí

BRINK, Antoinet. 2001. Conhecimento prévio e o Léxico: A teia construída no ensino de uma língua estrangeira, Polifonia, $n^{\circ}$ 4: 61- 74. 
CUNHA, Maria Jandyra Cavalcanti \& SANTOS, Percilia. Tópicos em português língua estrangeira. $1^{a}$. edição. Editora UnB, 2002.

FERNANDES, Nina João Seabra Amaral Braz. Relações Semânticas da sinonímia e antonímia: contribuindo para o desenvolvimento da competência lexical na aula de Português Língua Estrangeira. Porto, U. Porto, 2009. 139p. Dissertação (mestrado) - Mestrado em ensino de Portugues Língua Segunda/Língua Estrangeira. Faculdade de letras da universidade do Porto, 2009.

GATTOLIN, Sandra Regina Bultros. O Ensino de Vocabulário no Livro Didático e na voz do professor. In: ROTTAVA, Lucia. Santos, Sulany Silveira dos. Ensino e Aprendizagem de línguas: língua estrangeira. - ljuí: Ed. Unijuí, 2006.

MARTINEZ, Pierre. Didática de línguas estrangeiras. - São Paulo: Parábola Editorial, 2009.

SCARAMUCCI, Matilde V Ricardi. O projeto CELPE-Bras no âmbito do MERCOSUL: contribuições para uma definição de proficiência comunicativa. In: ALMEIDA FILHO, José Carlos Paes. Português para estrangeiros interface com o espanhos. - Campinas, SP: Pontes, 2001.

Como citar este artigo (Formato ABNT):

ESCARPINETE, Mariana L.; FERRAZ, Mônica Mano T. Expandindo a significação em sala de aula de PLE: Encaminhamentos a partir de atividades de livros didáticos. Id on Line Revista Multidisciplinar e de Psicologia, 2017, vol.11, n.37, p.160-177. ISSN: 1981-1179. 